\title{
Effects of Brand Local and Nonlocal Origin on Consumer Attitudes in Developing Countries
}

\author{
Rajeev Batra \\ School of Business Administration \\ University of Michigan \\ Venkatram Ramaswamy \\ School of Business Administration \\ University of Michigan \\ Dana L. Alden \\ College of Business Administration \\ University of Hawaii at Manoa \\ Jan-Benedict E. M. Steenkamp \\ Department of Marketing \\ Tilburg University, The Netherlands \\ S. Ramachander \\ Academy for Management Excellence \\ Madras, India
}

\begin{abstract}
This study tested whether, among consumers in developing countries, brands perceived as having a nonlocal country of origin, especially from the West, are attitudinally preferred to brands seen as local, for reasons not only of perceived quality but also of social status. We found that this perceived brand nonlocalness effect was greater for consumers who have a greater admiration for lifestyles in economically developed countries, which is consistent with findings from the cultural anthropology literature. The effect was also found to be stronger for consumers who were high in susceptibility to normative influence and for product categories high in social signaling value. This effect was also moderated by product category familiarity, but not by consumer ethnocentrism. The results, thus, suggest that in developing countries, a brand's country of origin not only serves as a "quality halo" or summary of product quality (cf. Han, 1989), but also possesses a dimension of nonlocalness that, among some consumers and for some product categories, contributes to attitudinal liking for status-enhancing reasons.
\end{abstract}

Consumers in developing markets are increasingly faced with a choice between older local brands and newer nonlocal or foreign brands. How they make this choice is obviously worth researching. Scores of studies have already documented the ways in which consumers use a brand's

Requests for reprints should be sent to Rajeev Batra, 4209F Business Administration Building, School of Business Administration, University of Michigan, Ann Arbor, MI 48109-1234. E-mail: rajeevba@umich.edu country of origin (CO) as a cue in inferring its quality and acceptability (Baughn \& Yaprak, 1993; Bilkey \& Nes, 1982), and this research ought to help us understand how consumers in developing countries make this choice between local and nonlocal brands. However, most analyses of $\mathrm{CO}$ effects have only used data from U.S. or U.K. consumers (see review in Heslop \& Papadopoulos, 1993). As a result, we are left with little theory to predict how and why consumers in developing markets choose between older, local brands and newer, foreign or nonlocal brands. To enhance our under- 
standing of such processes in developing versus developed country settings, the following study tested several hypotheses regarding the psychological mechanisms that underlie how a brand's origin, whether local or nonlocal, affects brand preference and choice in India, one of the world's fastest growing consumer markets.

Academic research on $\mathrm{CO}$ effects is now over 30 years old. Much of the initial research in this area sought to understand risk-reducing biases used by Western consumers when evaluating products from, among others, less-developed and, therefore, "risky" countries or regions. Schooler and Sunoo (1969), for example, studied biases among U.S. consumers against countries in Asia or Africa. Given this orientation, the $\mathrm{CO}$ literature has typically examined the role of the $\mathrm{CO}$ as a "halo" construct that influences product attribute quality beliefs, or as a construct that summarizes beliefs about product quality, and only then influences attitudes or purchase intentions (Han, 1989; Heslop \& Papadopoulos, 1993). Only recently has the literature begun to examine nonquality-related, direct effects of a brand's $\mathrm{CO}$ on brand attitudes or purchase intentions. For example, Klein, Ettenson, and Morris (1998) found among Chinese consumers an effect for country-specific animosity that reduces brand purchases from Japan, independent of judgments about the quality of those brands.

In this study, we hypothesized that $\mathrm{CO}$ effects in developing countries operate differently than suggested in the literature, which is largely based on developed country data. Specifically, we argue that, in developing countries, a brand's CO affects perceptions of nonlocalness. Such nonlocalness can be very favorable, especially if the $\mathrm{CO}$ has a Western or developed CO (e.g., the United States, Europe, or Japan). We believe that the nonlocal effect operates in addition to consumer assessments of the brand's quality ratings and is motivated primarily for the purpose of status enhancement. We also examined the extent to which the impact of a nonlocal $\mathrm{CO}$ is moderated by a consumer's admiration of the lifestyles in economically developed countries (EDCs). In addition, we studied other moderating factors, such as consumer ethnocentrism and familiarity with the product category. Our study covered a wide range of product categories, brands, and models and used consumer perceptions of a brand's localness and product quality, rather than relying only on researcher impressions.

\section{LITERATURE REVIEW AND HYPOTHESES}

Reviews of the scores of articles that have appeared on the topic of CO effects can be found in Bilkey and Nes (1982), Baughn and Yaprak (1993), and others. In brief, a brand's CO serves as an extrinsic cue (along with price and brand name) that supplements the use of intrinsic cues (perceptions of design, performance, etc.). Economic, cultural, and political perceptions of the $\mathrm{CO}$ in question determine its effect on brand evaluation (Han, 1989). Research on the CO (e.g., Parameswaran \& Pisharodi, 1994) has shown that CO image has multiple dimensions or facets (such as the strength of its economy, nature of its political system, technological competence, etc.). Nonetheless, previously studied $\mathrm{CO}$ effects primarily concerned its effect on a brand's presumed levels of intrinsic quality and performance and, therefore, its desirability (Bilkey \& Nes, 1982; Han, 1989). These effects of the CO have been found to vary across product classes and consumer types and tend to be smaller when other cues are available to the consumer (Papadopoulos, 1993).

\section{Evidence of Generalized Preferences for Nonlocal Brands in Developing Countries}

Another stream of the literature that is more anthropological in nature, however, suggests that consumers in developing countries also see the $\mathrm{CO}$ as determining a brand's desirability for symbolic, status-enhancing reasons (status preference), in addition to suggesting overall quality. Such generalized status preference for nonlocal (foreign) brands has been reported in developing countries, such as The People's Republic of China (Sklair, 1994), Vietnam (Schultz, Pecotich, \& Le, 1994), Nigeria (Arnould, 1989), the Democratic Republic of Congo (Friedman, 1990), Zimbabwe (Burke, 1996), Romania and Turkey (Bar-Haim, 1987; Ger, Belk, \& Lascu, 1993), and Ethiopia and Peru (Belk, 1988, p. 117).

In discussing Romania, Ger et al. (1993) noted that

Status goods are nearly inevitably foreign. This was true before the revolution, but then scarcity made such goods very hard to acquire. Now it is more a matter of their greater cost, plus their continued association with foreign lifestyles, that imparts status to their owners. (p. 104)

Concerning Turkey, they continued, "Consumption of foreign products is highly desirable ... The synonymity of progress with ever-present Westernization whets the appetite for the now-available foreign products ... status brands are mostly foreign" (p. 105). Sklair (1994) wrote of Chinese consumers that "everything foreign had an automatic cachet" (p. 269). Of Vietnam, Schultz et al. (1994) reported "western brand favoritism ... supplants local products" (p. 248). Finally, Burke (1996) wrote of Zimbabwe that "foreign items (had) an association ... with elite power and privilege" (p. 181).

Despite the strength of this research finding in the cultural anthropology literature, this status preference for foreign (especially Western) goods among consumers in developing countries appears to have been largely ignored in the standard $\mathrm{CO}$ literature. Hence, additional research on its existence, as well as its antecedents and consequences, is clearly needed. Neglect of this effect in the CO literature could be because this effect seems likely to be much stron- 
ger in developing than developed countries, where most of the $\mathrm{CO}$ research has originated.

\section{Why This Effect Is Stronger in Developing Countries}

All societies have processes of social comparison, ways of negotiating status and prestige, and markers of class. Researchers agree that the products and brands chosen by consumers often serve nonutilitarian functions, such as symbolic acquisition and communication of social distinctions, particularly status (Douglas \& Isherwood, 1979). Such concern with status display is even more important in developing countries, where interpersonal relationships are of prime importance (Ger et al., 1993, p. 105) and where, because of economic transition, income disparities and status mobility are high (Belk, 1988, p. 112; Kottak, 1990, pp. 49, 58). Indeed, times of transition and social mobility magnify the tendency to claim differential status through the brands one consumes (Luckmann \& Berger, 1964). Development economists, such as James (1993), argued that periods of economic development increase the importance of positional values, oriented toward conspicuous consumption and status display.

Given this greater salience of status markers in developing societies, several explanations for nonlocal products acquiring higher status than local products come to mind. First, in developing countries, imports are usually more expensive and more scarce than local products, making them more desirable from a reference group standpoint (Bearden \& Etzel, 1982). Writing of the Congo, Friedman (1990) said,

For the Congolese, identity is very much outside of ... the society. To realize oneself is to become "un grand," and the latter is manifested in its highest form in the best of the West, the most modern and latest design and the least accessible [italics added] ... The practice of identity here is the accumulation of otherness. (p. 324)

Second, consumers in developing countries are relatively less affluent than those in developed countries, and this can, quite naturally, create a sense of insecurity and inferiority (e.g., on the inferiority complex of Brazilians, see Kottak, 1990 , p. 38; and for comments about Indians, see Singh, 1982, p. 23). Consumers in developing countries, thus, often seek to emulate the apparently glamorous Western consumption practices and lifestyles and purchase the brands they are exposed to through movies and TV channels, Western tourists, their own workers gone overseas, and their own travel abroad. Because the production and control of popular culture resides in the affluent core countries of the West (especially the United States), the flow of media images is mostly from the economic center (the West) to the periphery (the developing world), making brands that symbolize affluent Western lifestyles seem highly desirable. Appadurai (1990, p. 299) identified different dimensions of this global cultural flow, including "mediascapes" ("large and complex repertoires of images, narratives and 'ethnoscapes' to viewers throughout the world, in which the world of commodities and the world of 'news' and politics are profoundly mixed"); Ger and Belk (1996) added "consumptionscapes" to his list. Belk (1988) wrote, "Besides the brands themselves, the consumer desire for these brands is one of the developed worlds' chief exports" (p. 117). This process has been labeled by some as a noncoercive form of "cultural imperialism"; see Tomlinson (1991) for a sophisticated critique.

Third, Hannerz (1990) pointed out that the desire to display competence with regard to alien cultures is an important motive behind the growth of "cosmopolitan" elites in many developing countries. Owning foreign brands is arguably a way of displaying such competency. Belk (1988) made the case that, although only such elites may actually consume in the Western manner, the desire to do so is widespread, both because of these outside influences and in imitation of the Westernized domestic elites in these counties. Arnould (1989) observed of Nigeria:

\begin{abstract}
Adopting the imagined trappings of the Western consumer, the Nigerian seeks to enter the community of the supranational elite, if only temporarily or only in his or her imagination ... emulation of imagined Western consumer behavior through goods encoding new experiences and aspirations prevails as part of their search for legitimacy of new roles. (pp. 259-260)
\end{abstract}

Finally, Venkatesh and Swamy (1994, p. 207) argued that consumers in developing economies today want to be able to participate in the global consumer community, living in this "imagined world" (cf. Appadurai, 1990), in part, through access to products from all over the world. However, not all consumers have the power to do so, leading to an aspirational yearning for many foreign-made brands. In Romania, for instance, only the nomenclatura, individuals who could travel to the West, could acquire such goods. Hence, possession of these goods (as well as knowledge of Western popular culture) was a source of great status. The fact that governments and traditional institutions often criticize such corrupting, hedonistic, alien values serves only to make them even more attractive to younger consumers, who see these goods as symbols of status, affluence, modernity, individuality, rebellion against traditional institutions, and freedom of choice (Bar-Haim, 1987). Very important for our present purposes, one consequence of attitude is a loss of confidence and pride in local goods and material culture, and (at least for awhile) a disregard for local products (Ger \& Belk, 1996, p. 283).

\section{The Indian Situation}

These factors are even more pronounced in India, the developing country in which this study was conducted. Although 
any discussion of "national character" is necessarily an oversimplification, some generalizations may nonetheless be offered. India has always had a very hierarchy- and status-conscious society (Kakar, 1981, p. 124), which began with the caste system and has now evolved into more of a class-based system (Venkatesh \& Swamy, 1994, p. 54). Thus, there has always been a search for signs and markers of status and class, and successful Indians frequently like to display their affluence through ostentatious displays of the goods they own (Singh, 1982, p. 27). India's closed economy, which only recently opened to the outside world, severely limited imports of Western consumer goods and made them scarce and expensive. Thus, it was natural for such goods to acquire such a symbolic status-giving role.

Ger et al. (1993, p. 106) pointed out that demand for foreign goods also goes up when a nation or culture goes through a period of lowered confidence or esteem, such as happened recently in Eastern and Central Europe, with the "defeat" of communism and statism. India has long had a history of being colonized by foreign rulers, most recently the British, and many social commentators have claimed that Indians still have an "inferiority complex" and a desire to imitate foreign-origin products and people. Tully (1991) wrote, "Colonialism teaches the native elite it creates to admire-all too often to ape-the ways of their foreign rulers. That habit of mind has survived in independent India" (p. 3). Naipaul (1964) said of India:

Its mimicry is both less and more than a colonial mimicry. It is the special mimicry of an old country which has been without a native aristocracy for a thousand years and has learned to make room for outsiders, but only at the top ... no people are as capable of mimicry as the Indians. (p. 60)

This meaning transfer of status and yearning to scarce Western brands has been magnified by (a) the large number of Indians with connections to the West (such as relatives living or working there, or traveling there); (b) exposure to Western tourists; (c) the widespread knowledge of English and thus greater comprehension of English-language media inflows; and more recently, (d) the very influential role played by TV (including satellite and cable channels) as a cultural and entertainment medium, disseminating exposure to Western lifestyles.

In addition, with the recent opening up of its markets and the changes in women's roles, India is now undergoing very significant changes, including rising incomes and changing expectations and tastes (Venkatesh \& Swamy, 1994, p. 207). As pointed out by Luckmann and Berger (1964), times of transition and social mobility magnify the tendency to claim differential status through the brands one consumes. As a result, more than ever before, today Indian consumers yearn to be equal participants in the global consumer economy, with the power to acquire brands made from all over the world, giving foreign-made products a cachet often not known in their home countries. Venkatesh and Swamy (1994) also claim that, because Indian consumers are long used to and sophisticated about symbolic religious iconography, India provides "a fertile soil" for the iconic images of brands.

For all these reasons, India seems to be a highly appropriate locale for testing the intrinsic appeal of a brand's nonlocal origin. Results obtained in India are unlikely to generalize exactly to all developing countries because there will obviously always be differences in how consumers in different developing countries respond to the local versus nonlocal nature of brands. However, one can reasonably argue that the same general phenomena are likely to recur across developing countries as they go through a process of economic change and modernization (Westernization). Both sets of processes usually lead to greater individual social mobility; (initially) greater income inequality; a decline in traditional institutions, such as religion and extended families; and the adoption of newer (more rationalistic and scientific) technologies, practices, and viewpoints (for discussions of modernization and Westernization, which are not identical but do share many similarities, see Inkeles \& Smith, 1974; Srinivas, 1966). As previously discussed at length, modern and sophisticated often come to be seen as connoted by the adoption of Western goods (Belk, 1988, p. 117). However, such trends are not irreversible or permanent. Some of this preference for foreign products is due to their novelty and to the desire of inexperienced consumers to buy better known and more trustworthy brands. As consumers become more knowledgeable, they may often return to local goods, and there is usually a "mixing-together" of local mores and foreign consumption habits (Arnould, 1989; Friedman, 1990; Ger \& Belk, 1996, p. 285). As Appadurai (1990) put it, the globalization of culture is not always the same as its homogenization.

\section{Interactions With Admiration of Lifestyle in Economically Developed Countries}

If consumers in developing countries tend to evaluate nonlocal brands more favorably for the reasons just discussed, this effect ought to be stronger the greater the degree to which the brand is seen as being nonlocal instead of local. In this study, we measured nonlocalness as the perception that the brand is marketed locally and in foreign countries, instead of only locally. ${ }^{1}$ Although some brands are clearly local (e.g., Taaza tea, in India), and others clearly nonlocal (e.g., Coca-Cola), many have a "hybrid" origin (e.g., BPL-Sanyo TV sets, in India). For this reason, we measured nonlocalness on an interval scale, although for brevity we refer simply to a

\footnotetext{
'In India, the site of this research--as in most other developing countries-local-origin brands are almost without exception sold only domestically, so that the fact that a brand is sold not only locally but also in many foreign markets clearly implies nonlocal origin.
} 
brand's local versus nonlocal origin. A brand is conceptualized as being more nonlocal than local if it is perceived to be marketed and consumed in other countries as well, not just in that local market. We thus first test our main effects hypothesis concerning perceived nonlocalness:

\section{H1: A brand's perceived degree of nonlocal origin will be significant in shaping consumer attitudes to- ward it, in a positive direction.}

More important, it follows from the aforementioned theoretical development that any such main effect of a brand's nonlocal origin (Hypothesis 1 ) should vary in strength across consumers in developing countries depending on their admiration of lifestyles in EDCs. Attitudes toward nonlocal brands ought to be higher for those who admire EDC lifestyles than for those who do not. Past research has found a stronger tendency to favor foreign $\mathrm{CO}$ products among consumers who had more favorable social contact with foreigners and among those who have a greater perceived similarity of interests and beliefs with the foreign $\mathrm{CO}$ in question (Heslop \& Papadopoulos, 1993, p. 63). By extension, EDC admiration ought to lead to more positive attitudes toward brands with higher perceived nonlocal $\mathrm{CO}$.

H2: A consumer's EDC admiration moderates the effect of perceived nonlocalness of a brand's origin on brand attitudes. As EDC admiration increases, the effect of perceived nonlocalness of the brand on brand attitude will become more positive.

\section{Other Individual Difference Characteristics Moderating the Effect of a Brand's Origin}

Ethnocentrism. Several CO researchers have found that many respondents in their studies preferred domestic products to foreign ones, although this bias varied across consumer segments and countries (Heslop \& Papadopoulos, 1993, pp. 44, 46). In the sociological literature, the construct of ethnocentrism describes the tendency of people to reject people who are culturally dissimilar, and at the same time to favor those who are more like themselves. Drawing on this literature, Shimp and Sharma (1987) developed the construct of consumer ethnocentrism and argued that highly ethnocentric consumers can be expected to avoid buying imported products because doing so would be unpatriotic, hurt domestic jobs, and so on. In contrast, nonethnocentric consumers should evaluate foreign products on the product's intrinsic merits, without downgrading them simply because of their foreign origin. In a variety of studies, Shimp and Sharma showed that U.S. consumers who scored high on ethnocentrism (measured on their CETSCALE) were indeed more favorably biased toward buying local products and more opposed to buying products manufactured in other countries. Similar effects were shown by Netemeyer, Durvasula, and Lichtenstein (1991).

Despite such research, it is not clear that, among more ethnocentric consumers, the "home product bias" for a brand identified with a particular $\mathrm{CO}$ will also exist for a brand's generalized degree of nonlocal origin. An issue recently raised in the literature concerns the possible diminution of $\mathrm{CO}$ effects as multinational companies (e.g., Coca-Cola, IBM, Philips, Sony) develop and leverage global brand names, marketing the same (or very similar) products under the same brand name in various markets, with these brands manufactured locally or regionally. This raises the question of whether CO-like effects persist even if consumers see a brand as having such a nonspecific or generalized foreign origin, instead of identifying it uniquely with one particular $\mathrm{CO}$ (Papadopoulos, 1993, p. 17). Samiee (1994) wrote,

To the extent that markets are global, the $\mathrm{CO}$ may be less important in the choice process ... in an era of global sourcing, manufacturing and marketing, coupled with a better informed audience influenced with increased levels of global communications, it is increasingly difficult to precisely define the CO of products. (p. 594)

It could thus be argued that the reduced identification of a brand with a particular $\mathrm{CO}$ might reduce ethnocentric sentiments against it.

On the other hand, it could be argued that even brands having this diffuse nonlocal image are evaluated by consumers in terms of their association with some primary $\mathrm{CO}-$ for example, Coca-Cola with the United States, or Sony with Japan (Papadopoulos, 1993). Papadopoulos pointed out that even though many of these products are manufactured in multiple locations across the world, they are still often positioned with respect to their national origins (e.g., Volkswagen cars). Some of these national origins are even fictitious (e.g., Reebok, a U.S. shoe company, uses the British flag). Tse and Gorn (1993) found, in a limited experimental study, that CO remained a salient and enduring factor in consumer evaluations even in the presence of a global brand name. Thus, given the weight of previous research on this issue, we hypothesized,

\section{H3: A consumer's ethnocentrism moderates the effect of perceived nonlocalness of a brand's origin on brand attitudes. As ethnocentrism increases, the effect of perceived nonlocalness of the brand on brand attitude will become less positive.}

In addition, this moderating effect of ethnocentrism should be less strong among consumers who admire EDC lifestyles than among those who do not. Among the former category of consumers, their desire to buy nonlocal brands (given their high EDC admiration), and their desire to buy only local brands (given their high ethnocentrism), should offset each other. For consumers who do not admire EDC 
lifestyles, however, these two forces work in concert, each working against the purchase of brands perceived to be nonlocal. Therefore, we hypothesized the following three-way interaction between ethnocentrism, perceived brand local or nonlocal origin, and admiration of the lifestyles in EDCs:

H4: The effects of consumer ethnocentrism, in making attitudes more positive for brands perceived as local, will be less strong among consumers who admire lifestyles in EDCs than among consumers who do not.

Susceptibility to normative influence. As discussed, it has been argued that nonlocal brands are preferred over local-only brands among consumers in developing countries for status reasons because the goods' origin gives them an "origin cachet" among the consumer's reference groups (Friedman, 1990; Hannerz, 1990). In the CO literature, Heslop and Papadopoulos (1993, p. 71) pointed out that CO effects have been found to be greater when consumers are looking for high status products. If this is true, it would seem that the kinds of consumers who place a premium on a brand's nonlocalness largely because of the status (self-image and reference group approval) benefits should be those who are more sensitive to what their reference groups think of them. This variable has never been tested in the $\mathrm{CO}$ research context.

Reference groups are groups used as standards for self-appraisal or as sources of personal norms and attitudes. Because we were concerned with the added value of a brand's origin that may arise from its ability to enhance the user's self-image and help the user gain social acceptance and approbation, we were concerned only with normative reference group effects. Susceptibility to such normative reference group influence has been conceptualized and measured most clearly by Bearden, Netemeyer, and Teel (1989) through an individual difference construct called the susceptibility to normative influence (SNI). It would seem logical that consumers who prefer nonlocal brands because of their "reference group appeal" should also be more susceptible to such normative influence.

However, the moderating effects of SNI should only apply when the ownership or use of that product category is socially visible, and it thus has high social and declarative value (sometimes referred to as "badge" products). Earlier research on moderators of reference group influence has found that such influence is stronger when the product category is more conspicuous and its ownership or consumption are more publicly visible (Bearden \& Etzel, 1982). Thus, CO effects should be stronger in product categories that serve a greater social signaling function, among high SNI consumers more sensitive to this social signaling function (i.e., a three-way interaction on brand attitudes should occur between perceived brand origin, SNI, and category social signaling value). We therefore hypothesized,

H5a: A consumer's susceptibility to normative influence moderates the effect of perceived nonlocalness of a brand's origin on brand attitudes, for product categories serving a social signaling function. For such product categories, as the consumer susceptibility to normative influence increases, the effect of perceived nonlocalness of the brand on brand attitude will become more positive.

In addition, these moderating effects of SNI should also be stronger among consumers who display a greater admiration of the lifestyles in EDCs because the reference groups of consumers with such high admiration for EDCs should place a higher value on nonlocal brands than on local brands. Thus, we also hypothesized a three-way interaction between perceived brand origin, SNI, and EDC lifestyle admiration:

H5b: Among consumers having a high admiration of the lifestyles in economically developed countries, a consumer's susceptibility to normative influence moderates the effect of the perceived nonlocalness of a brand's origin on brand attitudes. For such consumers with high admiration for EDC lifestyles, as their susceptibility to normative influence increases, the effect of perceived nonlocalness of the brand on brand attitude will become more positive.

The moderating role of product category familiarity.

As argued previously, a key reason why many consumers in developing countries prefer nonlocal over local brands is that the former conveys higher status. It seems reasonable that the contribution of a brand's origin to brand attitudes for these reasons should be moderated by some of the same factors that affect the contribution of other extrinsic cues (attributes such as price or brand name that are not part of the physical product itself; cf. Rao \& Monroe, 1988).

Generally speaking, intrinsic cues (such as design or performance) have a more powerful effect on quality judgments than do extrinsic cues, and extrinsic cues are used more often in product evaluations when intrinsic cues are not available (Steenkamp, 1989). The literature also suggests, however, that extrinsic cues are of greater significance when the consumer feels less able to judge the product's origin-free quality and thus feels more uncertain about how to choose brands in that category. This could arise because either the consumer lacks the necessary familiarity and expertise (Rao \& Monroe, 1988) or the product category is such that it is hard to judge objective quality.

Because nonlocal origin is clearly an extrinsic cue, it, therefore, should be used more often when consumers are less 
familiar with the product category and, thus, less likely to rely on quality alone in making judgments. This expectation is supported by previous research on single-country $\mathrm{CO}$ cues (Han, 1989). Similar results were found by Maheswaran (1994): Novices used CO information more than did experts, using them even when the attribute information was unambiguous, a pattern similar to the usage of other kinds of stereotypical information. Thus:

H6: Consumer usage of a brand's degree of perceived local or nonlocal origin as an attitude-determining cue will be greater when the consumer is less familiar with the product category.

Note that another product category characteristic, its social signaling value, was hypothesized earlier (Hypothesis 5a) to have a three-way interaction with the brand's perceived origin and with a consumer's SNI in shaping brand attitudes. Note also that a product category's level of perceived risk will be used later as a control variable in our analyses, although hypotheses regarding it will not be offered because this variable has already been studied extensively in the CO literature (e.g., Heslop \& Papadopoulos, 1993, p. 71; Lumpkin, Crawford, \& Kim, 1985).

\section{METHOD}

\section{Data Collection}

Although the use of probabilistically selected national samples is clearly preferable, practical problems make using large, quota-based urban samples that overweight respondents with higher socioeconomic backgrounds common practice in international research. For similar reasons, the data for this study were collected in the two largest cities in India (Bombay and Delhi) by a market research company that used personal, at-home interviews among 508 urban, mostly middle-class women. The respondents were selected with the use of quota sampling (to meet age and income category requirements) from multiple geographical locations within each city and were divided evenly between the two cities. A Hindi version of the questionnaire (verified to match the English version via back translation) was used when the respondent was not comfortable with the English version, and 25\% of the interviews were back checked by supervisors. Seventy-three percent of the women were between 25 and 54 years of age, $100 \%$ had completed high school (53\% had education beyond high school), and $85 \%$ were married.

Each respondent answered a questionnaire that included questions (among others) on background demographics, attitudes and psychographics, and "individual difference variable" scales (including consumer ethnocentrism, SNI, and admiration of lifestyles in EDCs). Then, for each of two product categories per respondent, questions were asked on product category familiarity. For each product category, each respondent then answered questions covering brand attitudes, brand image, brand quality, and the brand's perceived local or nonlocal origin about three brands. Questions were also asked on prior brand usage, brand familiarity and availability, and product category risk, for use as covariates. Details on the measures used in our analysis are presented later.

Across all respondents, data were collected on eight product categories, four brands per product category. Because of space or time limitations, the product categories were rotated across questionnaires, in sets of two categories for any one questionnaire. For each product category, the brands were also rotated across questionnaires. As a result, each respondent for a particular product category answered questions on two fixed brands and on a third brand that was alternated across respondents. ${ }^{2}$ Thus, whereas each respondent only provided data on three brands, data on four brands per category were collected across all respondents. This balancing and rotation were needed to keep each respondent's time demands within reasonable levels.

The total set of product categories was created purposively to provide variance across constructs of interest: consumer familiarity with the product category; product category social signaling value; level of technology used in the category and, thus, perceived risk; and the level to which local taste preferences might be expected to vary from those of other cultures. Using these criteria, we selected eight product categories: laundry detergents, wristwatches, soft drinks, light bulbs, toothpaste, washing machines, tea, and TV sets. Analysis of the mean levels and variances of these variables across these eight product categories (omitted for brevity) showed that on most characteristics (especially perceived risk and social signaling value), there appeared to be significant variation of individual category ratings relative to the mean.

As already mentioned, each individual respondent only answered questions on two product categories. Four brands in each product category were selected and a total set of 32 brands was created to provide variance in the perceived local or nonlocal origin construct of interest. Thus, some brands were clearly nonlocal (e.g., Ariel detergent, Coca-Cola, Timex watches, Philips TV sets, Taster's Choice tea), others were clearly local (e.g., Nirma detergent, Taaza tea, Limca soft drinks, HMT watches), whereas others were of blended or hybrid origin (e.g., TVS-Whirlpool washing machines, BPL-Sanyo TV sets, Lehar-Pepsi soft drinks), and so on.

\section{Measures}

The items used in our scales (see Table 1 for full details) were drawn to the maximum extent possible from scales

\footnotetext{
${ }^{2}$ Combining data from multiple respondents, when each respondent provides data on only a subset of stimuli, is standard research practice when the number of stimuli for any one respondent would otherwise become huge, as in blocked designs in conjoint analysis (Louviere, 1994).
} 
TABLE 1

Measures

\begin{tabular}{|c|c|}
\hline Scale & Item \\
\hline Consumer ethnocentrism ( $\alpha=0.63 ; M=4.81, S D=1.27$ ) & $\begin{array}{l}\text { Purchasing foreign-made products is un-Indian. } \\
\text { Indians should not buy foreign products, because this hurts Indian business and causes unemployment. } \\
\text { A real Indian should always buy Indian-made products. } \\
\text { It is not right to purchase foreign-made products. }\end{array}$ \\
\hline $\begin{array}{l}\text { Susceptibility to normative influence ( } \alpha=0.59 ; M=3.70 \text {, } \\
\qquad S D=1.26 \text { ) }\end{array}$ & $\begin{array}{l}\text { If I want to be like someone, I often try to buy the same brands they buy. } \\
\text { When buying products, I generally purchase those brands that I think others will approve of. } \\
\text { To be sure I buy the right product or brand, I often observe what others are buying and using. }\end{array}$ \\
\hline $\begin{array}{l}\text { Admiration of economically developed countries lifestyles } \\
\qquad(M=5.24, S D=1.42)\end{array}$ & $\begin{array}{l}\text { To what extent do you yourself admire the lifestyle of people who live in more economically } \\
\text { developed countries, such as the United States, Western Europe, and Japan? }\end{array}$ \\
\hline Brand attitudes ( $\alpha=0.67 ; M=5.23, S D=1.39$ ) & $\begin{array}{l}\text { Dislike/Like. } \\
\text { I have a negative (positive) opinion of it. }\end{array}$ \\
\hline $\begin{array}{l}\text { Perceived brand local/nonlocal origin ( } \alpha=0.63 ; M=4.19 \text {, } \\
\qquad S D=1.49 \text { ) }\end{array}$ & $\begin{array}{l}\text { I consider this brand to be an Indian (foreign) brand. } \\
\text { I don't (do) think consumers overseas buy this brand. } \\
\text { This brand is sold only in India (all over the world). }\end{array}$ \\
\hline Brand quality $(M=5.15, S D=1.44)$ & This is a very poorly made (well-made) brand. \\
\hline Brand image $(\alpha=0.69 ; M=4.90, S D=1.37)$ & $\begin{array}{l}\text { This brand has a very cheap/poor (good/high) image. } \\
\text { This brand really makes me look good (not too good) in front of my friends. }\end{array}$ \\
\hline Brand familiarity ( $\alpha=0.73 ; M=5.48, S D=1.44$ ) & $\begin{array}{l}\text { Not at all (very) familiar with it. } \\
\text { Never even heard of it (Know a lot of it). }\end{array}$ \\
\hline Brand availability $(\alpha=0.64 ; M=5.83, S D=1.29)$ & $\begin{array}{l}\text { This brand is easily (just not) available for me to buy. } \\
\text { I have seen (never seen) ads for it in Indian magazines, radio, or TV. }\end{array}$ \\
\hline Prior experience with brand ( $\alpha=0.79 ; M=3.48, S D=2.05$ ) & $\begin{array}{l}\text { Never tried it even once (Use it all the time). } \\
\text { I have no (extensive) personal usage experience with it. }\end{array}$ \\
\hline Category familiarity $(M=5.11, S D=1.60)$ & I am not at all familiar with this product category (Agree/Disagree). \\
\hline Category perceived risk ( $\alpha=0.64 ; M=4.79, S D=1.54$ ) & $\begin{array}{l}\text { It is (is not) a big deal if I make a mistake in choosing a (category). } \\
\text { A poor choice of (category) would (not) be upsetting. }\end{array}$ \\
\hline Category social signaling value $(M=4.69, S D=1.56)$ & Which (category) you select tells (doesn't tell) anything about a person. \\
\hline
\end{tabular}

Note. Almost all the scales have standardized alphas above 0.60 , the level suggested by Nunnally (1967) for scales still under development.

that have previously been validated in the literature, including consumer ethnocentrism (Shimp \& Sharma, 1987) and susceptibility to normative influence (Bearden et al., 1989), as well as the levels of category perceived risk and social signaling value (Laurent \& Kapferer, 1985). Unless otherwise indicated, these used strongly agree and strongly disagree endpoints. Admiration of the lifestyles in economically developed countries was measured through a single-item scale, "To what extent do you yourself admire the lifestyle of people who live in more economically developed countries, such as the United States, Western Europe, and Japan?" (not at all or very much). Viewing these countries or regions as part of one larger group of economically developed countries has lots of precedent: "First World" characterization continues in classifications by institutions, such as the World Bank.

For a brand's perceived local or nonlocal origin, consumers rated the degree to which, "I consider this brand to be an Indian (foreign) brand," "I don't (do) think consumers overseas buy this brand," and "This brand is sold only in India (is sold all over the world)." Because almost all India-made brands are only marketed within the country, the perception that India is only one of many markets for the brand clearly suggests a non-Indian origin for the brand. Brand attitudes were measured by using dislike or like and I have a negative (positive) opinion of it.

Because of potential questionnaire length, it was not possible for us to use the complete scales for some of the constructs of interest, which we would have preferred to do. The authors of some of the original scales have themselves used smaller subscales when confronted with such questionnaire length restrictions (e.g., Shimp \& Sharma, 1987), and such subscales have received support for their psychometric properties and validity (Netemeyer et al., 1991). In addition, such subscales have been used by other researchers (e.g., Klein et al., 1998, used only six of the original CETSCALE items). Principal components analyses were thus performed on data from a pretest to identify a subset of highly loading items from these scales that could be used without loss of validity. After examining these factor loadings, four items from CETSCALE (Shimp \& Sharma, 1987) were selected that had a coefficient alpha of 0.88 in the pretest, and three items that had a pretest alpha of 0.80 were selected from the original SNI scale.

The items finally used in each scale, along with the internal consistency coefficients (standardized alphas) as they emerged in the final Indian data, are in Table 1. Most items used 7-point ratings, and scores for relevant items were averaged in the case of multiple-item scales. The means and stan- 
dard deviations for the independent variables of theoretical interest are also shown in Table 1. All pairwise correlations between them were below 0.20 (except for brand familiarity, availability, and experience, which had higher correlations, in the $0.24-0.48$ range.)

\section{Creation of Key Analysis Variables}

Because prior research has shown that individuals rarely have full self-awareness about the source of their attitudes, it is hard to conceive of consumers answering validly and with full self-awareness any survey question that asks them what effect $\mathrm{CO}$ cues have in shaping their brand attitudes. This suggests the need to empirically estimate these effects by looking at the brand attitude difference for a nonlocal brand versus an otherwise equivalent local brand, keeping everything else constant. Because such an otherwise exactly equivalent local brand is going to be impossible to find a priori for every nonlocal brand studied, it becomes necessary to statistically control for other major, attitude-causing differences among them, particularly quality and image.

Using consumer ratings of their perceived quality and image for such statistical control purposes, however, is likely confounded by the fact that quality and image ratings of these brands might themselves be subconsciously influenced by their nonlocal versus local origin. This expectation was confirmed in the Indian data in which, across all 2,857 observations, the brand's image rating correlated 0.49 with its perceived local or nonlocal origin, and its quality rating correlated 0.31 with its perceived local or nonlocal origin. (Brand image and brand quality also correlated 0.45 with each other.) Because our key construct of interest is perceived brand local or nonlocal origin, these high correlation coefficients threaten the conceptual clarity of this vital construct (e.g., its discriminant validity from brand image). They also introduce the potential for multicollinearity because perceived brand local or nonlocal origin correlates much more with brand image at 0.49 than with brand attitudes, the dependent variable, at 0.34 . The following steps were taken to circumvent these problems:

1. Obtain the rating of each brand's perceived brand local or nonlocal origin from each consumer (through the measures described previously).

2. Obtain from each consumer the rating of that brand's quality, image, and attitudes toward that brand for each brand (these measures were also described earlier).

3. Use OLS brand-specific regressions to statistically estimate that portion of a brand's raw (initial) quality and image ratings that are explained by its perceived brand local or nonlocal origin and calculate the remainder (residual) not attributable to this perceived brand local or nonlocal origin.

4. Save these residuals as new variables named origin-free brand quality or origin-free brand image.
Through this partialling-out procedure, the correlation coefficients between perceived brand local or nonlocal origin and both the new origin-free brand quality and origin-free brand image variables were reduced to zero. This maximized the discriminant validity for these two new origin-free quality and image variables from perceived brand local or nonlocal origin. In addition, the correlation coefficient of origin-free quality with origin-free image was now lowered to 0.28 , which is much less likely to create multicollinearity difficulties. However, as desired, the origin-free brand quality data still correlate 0.87 with the raw quality ratings, and the origin-free brand image data still correlate 0.74 with the raw image ratings. Thus, these new origin-free brand quality and origin-free brand image variables, instead of the raw brand quality and brand image variables, were used in the attitude-predicting analysis.

\section{RESULTS}

Our hypotheses concerned the moderating effects of several individual-difference and product-category variables on the main effect of a brand's perceived local or nonlocal origin on attitudes toward the brand. To test these hypotheses, we conducted a linear regression analysis of consumers' brand attitude ratings as a function of (a) the brand's perceived local or nonlocal origin; (b) the brand's (origin-free) quality and image, as refined previously, and the consumer's brand familiarity, prior brand usage, and perception of the brand's local availability, to control for any confounding attitude-causing differences in the brands rated; (c) the main effects of the key individual difference (ethnocentrism, SNI, and admiration of EDC lifestyles) and category-related variables (category familiarity, category signaling, and category risk); (d) the two-way interactions of perceived brand local or nonlocal origin with each of the variables in item c; (e) the three-way interactions in Hypotheses 4, 5a, and 5b; and (f) a dummy variable for the product category because the data set pooled data from different product categories. ${ }^{3}$

All directional hypotheses can be tested by seeing if the sign of the estimated coefficient is in the hypothesized direction and is significant. Hypotheses about moderating effects can be tested via the statistical significance of the appropriate interaction term (cf. Baron \& Kenny, 1986). All variables were centered around their mean prior to analysis to facilitate

\footnotetext{
${ }^{3}$ These category dummies capture the mean-level differences across these product categories. We still retain the variables for the individual-level perceptions of that category's risk and familiarity because they modeled the variation around that category's mean level (captured by the added category dummy variable). The remaining variation in consumer attitudes across brands of varying local or nonlocal origin, and of varying risk or familiarity levels, was what we wanted to study. Note that adding dummies for the individual brands themselves would leave us only with variance within brand by individual, whereas our objective was to study variance across brands of varying origin by individual.
} 
the interpretation of interaction effects (Jaccard, Turrisi, \& Wan, 1990). All hypotheses were directional in nature, requiring the use of one-tailed tests of significance. The hypothesized signs of the coefficients of primary interest are thus indicated in parentheses in Table 2 (unstandardized $b s$ and standardized betas are both reported). The scales of the independent variables were reversed where necessary, prior to analysis, to lead to these expected signs.

The results of the regression analysis are shown in Table 2. Overall, $47.8 \%$ of the variance in brand attitudes was explained by this regression model, $F(31,2813)=83.03, p<$ .01 . Supporting Hypothesis 1 , it can be seen that the degree of perceived brand local or nonlocal origin has a significant, positive effect on brand attitudes $(b=0.276, p<0.01)$, indicating that the more a brand is seen as nonlocal, the more positive are the attitudes toward that brand. As stated in Hypothesis 2, the attitudinal effect of the perceived brand nonlocal origin was significantly more positive among consumers who are more admiring of EDC lifestyles (interaction term $b=.021, p<.02$ ) than among those who do not. Also note that, consistent with the literature on the determinants of brand equity, the brand-specific main effects of origin-free brand quality and origin-free image were also significant, as were the three covariates of brand availability, familiarity, and prior usage (all at $p<.0001$ ).

Turning to Hypothesis 3 , we find that ethnocentrism does not have a significant, negative, moderating impact on the effect of perceived brand local or nonlocal origin on brand attitudes $(b$ $=-.012, n s)$ This result is contrary to our hypothesis and is discussed later. Concerning Hypothesis 4, we had hypothesized that consumers higher in ethnocentrism would not have a reduced attitudinal preference for nonlocal brands if they admired EDC lifestyles. However, this three-way interaction between ethnocentrism, perceived brand local or nonlocal origin, and EDC lifestyle admiration was not significant. Thus, Hypothesis 4 was also not supported. Perhaps consumers who are ethnocentric are not likely to also be admiring of EDC lifestyles.

Hypothesis 5a argued that perceived nonlocal origin leads to more positive brand attitudes for high SNI consumers who buy products with high social signaling value. Because the three-way interaction of perceived brand local or nonlocal origin with SNI and category signaling value was significant $(b$

TABLE 2

Multiple Regression Analysis of Brand Attitudes

\begin{tabular}{|c|c|c|}
\hline Variable $^{\mathrm{a}}$ & Parameter Estimate & Standardized Estimate \\
\hline \multicolumn{3}{|l|}{ Main effects of perceived brand characteristics: } \\
\hline Perceived brand local/nonlocal origin & $0.276^{* *}$ & 0.296 \\
\hline Origin-free brand quality & $0.085^{* *}$ & 0.076 \\
\hline Origin-free brand image & $0.364^{* *}$ & 0.267 \\
\hline Brand availability (covariate) & $0.133^{* *}$ & 0.123 \\
\hline Brand familiarity (covariate) & $0.207 * *$ & 0.214 \\
\hline Prior experience with brand (covariate) & $0.149 * *$ & 0.220 \\
\hline \multicolumn{3}{|l|}{ Interactions of perceived brand local/nonlocal origin } \\
\hline \multicolumn{3}{|l|}{ Individual difference variables: } \\
\hline EDC admiration $(\mathrm{H} 2:+)$ & $0.021^{* *}$ & 0.031 \\
\hline Ethnocentrism (H3: -) & -0.012 & -0.016 \\
\hline EDC Admiration $\times$ Ethnocentrism $(\mathrm{H} 4:+)$ & 0.004 & 0.008 \\
\hline EDC Admiration $\times$ SNI (H5b: +) & $0.019 * *$ & 0.036 \\
\hline Category Signaling $\times$ SNI $($ H5a: +$)$ & $0.016^{* *}$ & 0.036 \\
\hline SNI & -0.006 & -0.008 \\
\hline \multicolumn{3}{|l|}{ Perceived category characteristics: } \\
\hline Category familiarity (H6: -) & $-0.020 * *$ & -0.034 \\
\hline Category risk & $0.015^{* *}$ & 0.026 \\
\hline Category signaling & 0.003 & 0.004 \\
\hline \multicolumn{3}{|l|}{ Other control effects: } \\
\hline Ethnocentrism & $0.032^{* *}$ & 0.029 \\
\hline SNI & $-0.034 * *$ & -0.031 \\
\hline EDC admiration & $-0.036^{* *}$ & -0.037 \\
\hline EDC Admiration $\times$ Ethnocentrism & $0.036^{* *}$ & 0.046 \\
\hline EDC Admiration $\times \mathrm{SNI}$ & -0.002 & -0.002 \\
\hline Category familiarity & -0.001 & -0.001 \\
\hline Category risk & $0.044^{* *}$ & 0.049 \\
\hline Category signaling & $-0.021^{*}$ & -0.024 \\
\hline Category Signaling $\times$ SNI & -0.012 & -0.018 \\
\hline Intercept & $5.129 * *$ & 0.000 \\
\hline
\end{tabular}

Note. Coefficients for category dummy variables not shown for brevity. $\mathrm{H}=$ hypothesis; $\mathrm{EDC}=$ economically developed country; $\mathrm{SNI}=$ susceptibility to normative influence.

${ }^{\mathrm{a}} \mathrm{Hypothesized} \mathrm{direction} \mathrm{of} \mathrm{effect} \mathrm{in} \mathrm{parentheses.}$

${ }^{*} p<0.10 .{ }^{* *} p<0.05$ 
$=.016, p<.01$ ), with each main effect and two-way interaction already in the model, this hypothesis was supported. Similarly, support was found for Hypothesis $5 \mathrm{~b}$, which stated that brands with a nonlocal origin lead to more positive attitudes among high SNI consumers who also have high admiration of EDC lifestyles: The three-way interaction of perceived brand local or nonlocal origin with $\mathrm{SNI}$ and admiration of EDC lifestyles was significant $(b=.019, p<.01$ ).

What about the moderating role of product category familiarity? As hypothesized earlier (Hypothesis 6), a brand's perceived local or nonlocal origin might serve more strongly as a quality cue for product categories with low familiarity. Supporting this hypothesis, the variable category familiarity did have a significant negative interaction $(b=-0.020, p<.01)$ with perceived brand local or nonlocal origin. Note that the category risk control variable was also significant at $p<.05$, consistent with prior results in the literature (e.g., Lumpkin et al., 1985).

\section{Additional Analysis of Mediation}

Recall that we argued in our theoretical development that the focus of this article-the status preference by consumers in developing countries for nonlocal over local brands because of admiration of EDC lifestyles and cultures-was in addition to the quality-related preference previously studied in the $\mathrm{CO}$ literature. To further support this argument, it is necessary to show that the effect of EDC admiration on brand attitudes is not occurring largely through (i.e., is not mediated by) judgments of the brand's quality, but instead occurs directly, at least in part.

A formal analysis of mediation was, therefore, conducted by using the procedure of Baron and Kenny (1986). For EDC admiration of perceived brand nonlocalness to affect brand attitudes through brand quality, (a) the interaction of EDC admiration with perceived brand nonlocalness must significantly affect brand attitudes; (b) this EDC admiration by perceived brand nonlocalness interaction term must affect brand quality; (c) brand quality must affect brand attitudes; and (d) the effect of the EDC admiration interaction with perceived brand nonlocalness, on brand attitudes, must disappear or substantially diminish when the mediator (brand quality) is introduced into the equation. These estimates were obtained through a series of regression equations, each of which also contained all the control and covariate variables discussed earlier, in addition to the necessary subset of these three variables (EDC admiration interacting with perceived brand nonlocalness; brand quality; brand attitudes). Results showed that although (a) EDC admiration by brand nonlocalness did significantly affect brand attitudes at $p<$ .04 , (b) it did not affect brand quality. Thus, equations (c) and (d) become irrelevant. These results held both for the origin-free brand quality variable and the raw brand quality variable. Results were similar if (a) was EDC admiration itself, instead of the interaction term of EDC admiration with perceived brand nonlocalness. We concluded that the data are consistent with our theoretical argument that the effect of EDC admiration on brand attitudes was not occurring simply because of a higher quality inference.

\section{DISCUSSION}

In this study we found that among consumers in developing countries, for reasons that go beyond brand quality assessments, brands perceived as having a nonlocal $\mathrm{CO}$ are attitudinally preferred to brands seen as local. Furthermore, the results indicate that such attitudinal enhancement increases with the degree of perceived nonlocalness. This suggests that a brand's $\mathrm{CO}$ not only serves as a quality halo or summary of product quality (cf. Han, 1989), but can also possess an additional dimension-that of the degree of foreignness or nonlocalness. Among some consumers and for some product categories, this dimension can contribute to attitudinal liking for the brand. We found this attitudinal effect was stronger for consumers high in SNI for product categories high in social signaling value, which is consistent with our status-enhancement explanation.

Among the consumers in developing countries that we studied, the effect was especially strong among high SNI consumers who also had high EDC admiration. Drawing from the cultural anthropology literature, we developed a theoretical framework showing why, among consumers in developing countries, brands seen as being sourced overseas (especially from the Western center) are seen as endowing prestige and cosmopolitanism and, thus, as enhancing the buyer's social identity (Friedman, 1990; Hannerz, 1990). As shown in our additional analysis of mediation, these attitude-enhancing effects are in addition to those caused by the perceived origin-free quality of these brands, which we used as a separate and unconfounded variable in our model through partialling out and estimation procedures.

We also studied a few other important moderating effects. Here, we found that the local or nonlocal origin effect was not weaker among more ethnocentric consumers, a finding that differs from most prior research. This has an interesting and potentially important implication: A brand seen as generally nonlocal (our operationalization), instead of coming from one specific country (as in prior CO research), may simply not evoke as much hostility from ethnocentric consumers as has been found in prior $\mathrm{CO}$ research. Support was also found for the theoretical expectation that this local or nonlocal perception effect is greater when the consumer felt a greater need to use quality cues because of lower familiarity with the category (after controlling for levels of perceived risk in the category). These results add to the literature on the use by consumers of extrinsic cues about quality (cf. Steenkamp, 1989).

As mentioned in the introductory paragraphs, most previous research has approached $\mathrm{CO}$ effects from the perspective of consumers in developed countries, where a brand's $\mathrm{CO}$ is used primarily as a risk-reducing cue (Heslop \& Papadopoulos, 1993). In contrast, this study examined CO effects from the perspective of consumers from developing 
countries, where a brand's nonlocal origin has been argued to symbolize cosmopolitanism and prestige, at least among certain consumer segments (those with high EDC admiration and high SNI levels), for product categories that have high signaling value. It is important to note that our study examined a brand's diffuse nonlocal image, instead of single-country $\mathrm{CO}$ cues, because of the predominance of global brands in developing country markets. Together, these findings add to our knowledge of consumer-level moderators of CO-like effects, expand our theoretical understanding of some consequences of ethnocentrism and SNI, and add to the nomological network for these constructs (cf. Bearden et al., 1989; Shimp \& Sharma, 1987).

Lending value to these findings are the nature of these data and the analytic techniques used in this study. The data come from carefully conducted personal interviews, from a reasonably large sample of adult Indian consumers (homemakers). They cover 32 brands (varying across the nonlocal-local continuum) from eight very different product categories, covering a range of perceived risk, category familiarity, and so on. The key constructs (brand attitudes, perceived brand local or nonlocal origin, consumer characteristics, category characteristics, etc.) are all based on respondent ratings, instead of being assumed by the researcher (e.g., how nonlocal a brand is, how risky a category is, etc.). Samiee (1994, pp. 588, 593) highlights the importance of measuring such consumer perceptions, given that a brand's $\mathrm{CO}$ and country of manufacture often differ, and because many brands have been considered local in more than one country (e.g., Singer in the United Kingdom, the United States, Germany, etc.). Care has also been taken in the analysis to partial out the effects of a brand's perceived local or nonlocal origin from its quality and image ratings. These origin-free quality and image ratings were then used in the model, along with the brand's perceived local or nonlocal origin, to estimate the effect of the latter on brand attitudes. Other covariates (such as brand familiarity, brand prior usage, and category perceived risk) were used to reduce error variance and the chances of a misspecified model.

\section{Future Research}

Perhaps the key finding of this study was that, among the consumers in developing countries examined here, consumers with high EDC admiration tended to have more positive attitudes toward brands marketed nonlocally (Hypothesis 2). A brand's perceived nonlocalness may thus be a significant reason why certain nonlocal brands face strong consumer demand in such developing countries, over and above the advantages of intrinsic quality and lower costs highlighted by Levitt (1983). If replicated, this finding has the implication for marketing practice that emphasizing foreign acceptance and origin may help rather than hurt the brand in developing countries where Western brands are held in high esteem. This finding also suggests the need for future research on the phenomenon of global brands, including work to clarify the meaning and measurement of that construct. Research also needs to examine how such perceptions of globalness are formed through marketing communications.

Data are also needed from multiple countries to see if our results generalize. It is possible, for instance, that the level of socioeconomic modernity of the developing country involved might affect the generalizability of our results. It is possible that the moderating role of EDC admiration, for instance, might be reduced in countries with a higher level of socioeconomic modernity. Furthermore, it may be that our results concerning the moderating effects of ethnocentrism and SNI might vary depending on the degree of collectivism in the country concerned. Both ethnocentrism and SNI deal with the ideas of groups and adherence to group norms, which ought to differ depending on the degree of collectivism in a culture. Whereas India is relatively less collectivistic, other developing countries (such as China) are more so. Future studies should also collect data on brands originating from a wider range of developed-country $\mathrm{COs}$ to study how the image of the particular $\mathrm{CO}$ moderates the nonlocalness preference effects found in this study. In addition, our theoretical discussion about the differences in $\mathrm{CO}$ processes in developed versus developing countries also need to be more rigorously tested through the collection and comparative analysis of data from both types of countries.

Work is also needed to improve the measurement quality of some of the scales we used, especially the generation and testing of additional items for scales in which we only used one item (e.g., category familiarity and category signaling value), because questions can be raised about their validity. It could be argued, for instance, that our category familiarity results appear analogous to those one would expect for category knowledge, even though our scale did not explicitly refer to the degree of knowledge about the category. Relatedly, research is needed to refine the construct of admiration of EDC lifestyles, which appeared to be a crucial interaction variable. The interactions with it (Hypotheses 2 and 5b) support the argument of Batra, Myers, and Aaker (1996) that "it is possible that the apparent increase in demand across the world for certain well-known brands such as Coca-Cola and Levi's is largely because they are seen by consumers ... as symbols of the freedom and affluent lifestyles of the West, and not because they are seen as global brands per se" (p. 716). Thus, what may sometimes matter more than a brand's nonlocalness is its Western icon-ness. This hypothesis, and constructs to measure it, also warrant future research using multicountry data.

\section{ACKNOWLEDGMENTS}

We gratefully acknowledge the financial support of the Academy for Management Excellence, Madras, India; the William Davidson Institute; the University of Michigan Business School; and the Center for International Business Education at the University of Michigan, in supporting the data collection for the study reported in this article. We thank the special issue editors and reviewers for their helpful comments. 


\section{REFERENCES}

Appadurai, A. (1990). Disjuncture and difference in the global cultural economy. Theory, Culture and Society, 7, 295-310.

Arnould, E. J. (1989). Toward a broadened theory of preference formation and the diffusion of innovations: Cases from Zinder Province, Niger republic. Journal of Consumer Research, 16, 239-267.

Bar-Haim, G. (1987). The meaning of Western commercial artifacts for eastem European youth. Journal of Contemporary Ethnography, 16, 205-226.

Baron, R. M., \& Kenny, D. A. (1986). The moderator-mediator variable distinction in social psychological research: Conceptual, strategic, and statistical considerations. Journal of Personality and Social Psychology, $51,1173-1182$.

Batra, R., Myers, J. G., \& Aaker, D. A. (1996). Advertising management (5th ed.). Upper Saddle River, NJ: Prentice Hall.

Baughn, C. C., \& Yaprak, A. (1993). Mapping country-of-origin research: Recent developments and emerging avenues. In N. Papadopoulas \& L. Heslop (Eds.), Product-country images: Impact and role in international marketing (pp. 89-116). New York: International Business Press (Haworth).

Bearden, W. O., \& Etzel, M. J. (1982). Reference group influence on product and brand purchase decisions. Journal of Consumer Research, 9, 183-194.

Bearden, W. O., Netemeyer, R. G., \& Teel, J. E. (1989). Measurement of consumer susceptibility to interpersonal influence. Journal of Consumer Research, 15, 473-481.

Belk, R. W. (1988). Third world consumer culture. In E. Kumcu \& A. F. Firat (Eds.), Research in marketing: Supplement 4. Marketing and development: Toward broader dimensions (pp. 103-127). Greenwich, CT: JAI.

Bilkey, W. J., \& Nes, E. (1982). Country-of-origin effects on product evaluations. Journal of International Business Studies, 8, 89-99.

Burke, T. (1996). Lifebuoy men, luxwomen. Durham, NC: Duke University Press.

Douglas, M., \& Isherwood, B. (1979). The world of goods: Towards an anthropology of consumption. New York: Basic Books.

Friedman, J. (1990). Being in the world: Globalization and localization. Theory, Culture \& Society, 7, 311-328.

Ger, G., \& Belk, R. W. (1996). I'd like to buy the world a coke: Consumptionscapes of the "less affluent" world. Journal of Consumer Policy, 19, 271-304.

Ger, G., Belk, R. W., \& Lascu, D. N. (1993). The development of consumer desire in marketing and developing economies: The cases of Romania and Turkey. In L. McAlister \& M. L. Rothschild (Eds.), Advances in consumer research (Vol. 20, pp. 102-107). Provo, UT: Association for Consumer Research.

Han, C. M. (1989). Country image: Halo or summary construct? Journal of Marketing Research, 26, 222-229.

Hannerz, U. (1990). Cosmopolitans and locals in world culture. Theory, $\mathrm{Cul}$ ture \& Society, 7, 295-310.

Heslop, L. A., \& Papadopoulos, N. (1993). But who knows where or when: Reflections on the images of countries and their products. In N. Papadopoulas \& L. Heslop (Eds.), Product-country images: Impact and role in international marketing (pp. 39-75). New York: International Business Press (Haworth).

Inkeles, A., \& Smith, D. (1974). Becoming modern. Cambridge, MA: Harvard University Press

Jaccard, J., Turrisi, R., \& Wan, C. K. (1990). Interaction effects in multiple regression (Sage University Papers Series on Quantitative Applications in the Social Sciences). Newbury Park, CA: Sage.

James, J. (1993). Consumption and development. New York: St. Martin's Press.

Kakar, S. (1981). The inner world: A psycho-analytic study of childhood and society in India. Delhi, India: Oxford University Press.
Klein, G. J., Ettenson, R., \& Morris, M. D. (1998). The animosity model of foreign product purchase: An empirical test in the People's Republic of China. Journal of Marketing, 62, 89-100.

Kottak, C. P. (1990). Prime time society, Belmont, CA: Wadsworth.

Laurent, G., \& Kapferer, J. N. (1985). Measuring consumer involvement profiles. Journal of Marketing Research, 22, 41-53.

Levitt, T. (1983). The globalization of markets. Harvard Business Review, 6l(3), 92-102.

Louviere, J. J. (1994). Conjoint analysis. In R. P. Bagozzi (Ed.), Advanced methods of marketing research (pp. 223-259). Cambridge, England: Blackwell.

Luckmann, T., \& Berger, P. (1964). Social mobility and personal identity. Archives Europeenes de Sociologie, 5, 331-344.

Lumpkin, J. R., Crawford, J. C., \& Kim, G. (1985). Perceived risk as a factor in buying foreign clothes. International Journal of Advertising, 4, 157-171.

Maheswaran, D. (1994). Country of origin as a stereotype: Effects of consumer expertise and attribute strength on product evaluations. Journal of Consumer Research, 21, 354-365.

Naipaul, V. S. (1964). An area of darkness. London: Andre Deutsch.

Netemeyer, R. G., Durvasula, S., \& Lichtenstein, D. R. (1991). A cross-national assessment of the reliability and validity of the CETSCALE. Journal of Marketing Research, 28, 320-327.

Papadopoulos, N. (1993). What product and country images are and are not. In N. Papadopoulas \& L. Heslop (Eds.), Product-country images: Impact and role in international marketing (pp. 3-38). New York: International Business Press (Haworth).

Parameswaran, R., \& Pisharodi, R. M. (1994). Facets of country of origin image: An empirical assessment. Journal of Advertising, 23, 43-56.

Rao, A. R., \& Monroe, K. B. (1988). The moderating effect of prior knowledge on cue utilization in product evaluations. Journal of Consumer Research, 15, 253-264.

Samiee, S. (1994). Customer evaluation of products in a global market. Journal of International Business Studies, 25, 579-604.

Schooler, R. D., \& Sunoo, D. H. (1969, March). Consumer perceptions of international products: Regional vs. national labeling. Social Science Quarterly, 50, 886-890

Schultz, C. J., II, Pecotich, A., \& Le, K. (1994). Changes in marketing activity and consumption in the Socialist Republic of Vietnam. In C. J. Schultz, II, R. W. Belk, \& G. Ger (Eds.), Research in consumer behavior (Vol. 7, pp. 225-257). Greenwich, CT: JAI.

Shimp, T. A., \& Sharma, S. (1987). Consumer ethnocentrism: Construction and validation of the CETSCALE. Journal of Marketing Research, 24 , 280-289.

Singh, K. (1982). We Indians. New Delhi, India: Orient Paperbacks.

Sklair, L. (1994). The culture-ideology of consumerism in urban China: Some findings from a survey in Shanghai. In C. J. Schultz, II, R. W Belk, \& G. Ger (Eds.), Research in consumer behavior (Vol. 7, pp. 259-292). Greenwich, CT: JAI.

Srinivas, M. N. (1966). Social change in modern India. Berkeley: University of California Press.

Steenkamp, J. B. (1989). Product quality. Assen, The Netherlands: Van Gorcum.

Tomlinson, J. (1991). Cultural imperialism: A critical introduction. Baltimore: John Hopkins University Press.

Tse, D. K., \& Gorn, G. J. (1993). An experiment on the salience of country-of-origin in the era of global brands. Journal of International Marketing, 1, 57-76.

Tully, M. (1991). No full stops in India. New York: Viking.

Venkatesh, A., \& Swamy, S. (1994). India as an emerging consumer society-A cultural analysis. In C. J. Schultz, II, R. W. Belk, \& G. Ger (Eds.), Research in consumer behavior (Vol. 7, pp. 193-223). Greenwich, CT: JAI

Accepted by Durairaj Maheswaran. 